\title{
O Cultivo da palaVra EM “poÉtica RURAL”, de Marilza Ribeiro
}

Talita Cristina Bandeira de FigUEIREDO*

Célia Maria Domingues da Rocha REIS**

Vinicius CARVALHO PEREIRA***

RESUMO

Neste artigo investigamos como o poema "Poética Rural", de Marilza Ribeiro, problematiza o processo da escritura de poesia. O poema constitui-se como um exercício metalinguístico, no qual o labor da criação poética é apresentado por meio da metáfora do trabalho rural. Por meio da análise dos aspectos formais que conferem sentidos ao texto e com o suporte da semiologia literária, demonstramos como o poema reflete os conceitos de morte do autor, polissemia da linguagem poética e literatura como trapaça na língua, caros ao pós-estruturalismo francês. Nos versos analisados, verifica-se como o eu lírico joga com a língua e elabora a linguagem poética pela atividade agrícola.

PalaVras-chave: Marilza Ribeiro, Poesia, Metalinguagem.

\section{INTRODUÇÃO}

Neste trabalho, analisamos o poema "Poética Rural", de Marilza Ribeiro, como um exemplo de texto intransitivo que problematiza o papel do escritor na elaboração da obra. Conforme os moldes da poesia

* Mestranda em Estudos da Linguagem, na Universidade Federal do Mato Grosso (UFMT), Cuiabá, Mato Grosso, Brasil. E-mail: talitacbf@gmail.com

** Professora do Departamento de Letras e do Mestrado em Estudos da Linguagem da Universidade Federal do Mato Grosso (UFMT), Cuiabá, Mato Grosso, Brasil. E-mail: celiadr@uol. com.br

*** Professor do Departamento de Letras e do Mestrado em Estudos da Linguagem da Universidade Federal do Mato Grosso (UFMT), Cuiabá, Mato Grosso, Brasil. E-mail: viniciuscarper@gmail.com 
contemporânea, o poema não possui rimas nem regularidade métrica. Composto por apenas uma estrofe de 26 versos, trata-se de um exercício metalinguístico, no qual o labor da criação poética é apresentado por meio da metáfora do trabalho rural. A reflexão sobre a escritura se dá na forma de uma voz feminina que equipara o processo da escrita ao cultivo de plantas.

A reflexão sobre o fazer poético é, para além da teoria literária, tema da própria poesia. A partir de diferentes paradigmas, escritores elaboram poemas sobre o processo de criação, as origens e finalidades da escritura poética. Nesse contexto, o poema escolhido como objeto desta pesquisa é representativo de uma escritura que nega a voz autoral ao ser origem determinadora do sentido do texto. Trata-se de uma visão discutida pela literatura desde os adventos da modernidade, como podemos verificar no emblemático poema "Un coup de dés", de Mallarmé, o qual, segundo Octavio Paz, "nega a possibilidade de dizer algo absoluto, consagração da impotência da palavra, é ao mesmo tempo o arquétipo do poema futuro e a afirmação plena da soberania da palavra" (1982, p. 334).

Desse modo, nossa investigação parte dos pressupostos pós-estruturalistas da semiologia literária, que reconhecem o caráter imanente da literatura, como jogo de - e da - linguagem. Partindo de uma análise focada na matéria textual, demonstramos como o poema versa sobre o modo pelo qual a linguagem poética instaura um regime polissêmico que desafia o fascismo da língua, conforme afirma Roland Barthes (2004).

\section{O CUltivo DA PALAVRA}

Marilza Ribeiro é uma poetisa contemporânea mato-grossense que possui alguns livros já publicados e examinados pela crítica literária. Sua obra, no entanto, ainda está em construção, uma vez que a poeta continua em atividade. Há em seu repertório diversos escritos inéditos que estão sendo compilados e organizados para futuras publicações. Alguns deles já foram apresentados à comunidade literária e acadêmica em forma de impressões avulsas e declamações públicas. Entre eles, está o poema investigado neste trabalho: 


\section{PoÉtica Rural}

Sou camponesa

Esparramo pela terra palavras-sementes

signos-férteis

brotando como trigais do sentido

dourando enunciados

Minha palavra-poesia

fruto e semente

rompendo pelos campos

turbulência do imaginário

feito searas

enormes safras colhidas

pelos olhares com fome

do saber profundo

Palavras-árvores

mognos... ipês... aroeiras... oliveiras...

cerejeiras... pessegueiros... mangueiras...

Sou camponesa e jardineira

planto em minha roça

sílabas, metáforas, frases

tudo floresce e frutifica

sentindo a memória das raízes

escrita enigmática

saindo do fundo

mais profundo do meu fundo

tão fecundo

dentro de mim.

(RIBEIRO, no prelo).

Logo no primeiro verso, a voz lírica afirma: "Sou camponesa". Essa definição de sua identidade poderia levar-nos a crer que o poema tratará, de fato, do ofício do trabalhador rural, mas logo percebemos 
indícios de que o eu lírico versa sobre o exercício de criação literária: "Esparramo pela terra palavras-sementes".

A composição de "palavras-sementes" se dá pela união dos substantivos "palavras" e "sementes", criando nova entidade discursiva. O termo une vocábulos de campos lexicais aparentemente distintos: enquanto "palavras" referem-se ao campo da língua, "sementes" remetem à noção de cultivo. Essa união demonstra que a camponesa que se apresenta no poema tem um ofício ambíguo. Sua lida funde o trabalho com a palavra e o trabalho com a semente. No decorrer do poema, escritura e cultivo são referenciados de forma indistinta, como se fizessem parte de um mesmo processo. Embora jamais se proclame escritora, a voz lírica afirma-se como tal de forma metafórica pela identidade da camponesa. Assim, fica demonstrado que o objeto de trabalho dessa camponesa são as palavras e que, portanto, o ato de esparramar "palavras-sementes" pela terra é equivalente ao ato de escrever.

No decorrer dos versos, observamos uma abundância de termos referentes ao domínio agrícola, como "terra", "trigais", "fruto", "semente", "campos", "searas", "safras" etc. A exploração do plantio como representação para o ato da escrita permite-nos perceber as palavras como seres vivos que, assim como as plantas, crescem, florescem e frutificam. Trata-se de uma prosopopeia que vivifica a linguagem. À ideia de vida na linguagem subjaz o conceito de morte do autor, apresentado por Roland Barthes:

Sem dúvida que foi sempre assim: desde o momento em que um fato é contado, para fins intransitivos, e não para agir diretamente sobre o real, quer dizer, finalmente fora de qualquer função que não seja o próprio exercício do símbolo, produz-se este defasamento, a voz perde a sua origem, o autor entra na sua própria morte, a escrita começa. (BARTHES, 1998, p. 65).

No poema, a linguagem ganha um estatuto de ser vivo vegetal que pode prescindir de cuidados humanos, pois, após semeada, a natureza da poesia/planta encarrega-se de fazer com que ela cresça sem a mão do homem. A linguagem precede o homem, logo não pode ser criada por ele. Assim, ao apresentar-nos uma escritora na condição de 
camponesa e as palavras como sementes, o poema leva-nos a crer que a autora não é criadora de sua obra, mas mera cultivadora dela.

Há apenas dois verbos em primeira pessoa que denotam a ação direta da camponesa no cultivo: "esparramo" e "planto", nos versos 2 e 18, respectivamente. Com eles, percebe-se que o papel da voz lírica resume-se a dar início à plantação. Ela fecunda a terra com as sementes, mas o que se segue independe de suas ações, como podemos ver pelo emprego de verbos que denotam o desenvolvimento da planta por si própria:

signos-férteis

brotando como trigais do sentido

dourando enunciados

$[\ldots]$

fruto e semente

rompendo pelos campos,

[...]

tudo floresce e frutifica

Mesmo nos cinco versos finais, ao afirmar que a escrita vem de dentro do eu lírico, o poema não apresenta indícios de que a camponesa seja a responsável direta pelo surgimento dessa escrita, uma vez que ela não é arrancada ou puxada para fora pela camponesa. A agricultora é um agente passivo no processo, alguém que sofre a ação perpetrada pela linguagem. Os elementos plantados - sílabas, metáforas, frases sofrem a ação frutificadora da poesia, que age nas profundezas da camponesa e de lá sai, como podemos ver pela construção sintática em que o sujeito da ação é a "escrita":

escrita enigmática

saindo do fundo

A poetisa é como alguém que lida com a linguagem, não alguém que a cria. Outro indício da negação do autor enquanto criador está no fato de que a plantação remete a um rastro. As plantas crescidas atestam a passagem de um agricultor que semeou a terra, mas este se torna dis- 
pensável em seguida, pois a palavra poética brota por si mesma, saindo do fundo da página e do arado.

A esse respeito, vale lembrar que Derrida (1973) já havia articulado as noções de escrita, rastro e agricultura, ao designar a passagem do grámma ao greffe ("enxerto", em francês), e do greffe ao graphe ("grafo", em francês), como balizas da história da escrita. Afinal, desde a pré-história, quando ainda não se conheciam os sistemas alfabéticos, ideográficos ou pictóricos, os humanos vêm rabiscando paredes com tintas vegetais, sangue, ou mesmo instrumentos pontiagudos abrasivos, escalavrando rastros ambíguos - grámmas (DERRIDA, 2008).

Do grámma ao greffe, foi um passo para as culturas agrícolas no período neolítico, as quais aprenderam a deitar seus traços e rastros sobre a vegetação, imprimindo uma marca humana às plantas fundidas por meio de enxertia. Se o enxerto nasce de um sulco aberto pelo homem, hibridizando duas espécies vegetais distintas, é ao vegetal que cabe fazer viver essa criatura mista, que se alimenta de uma seiva extraída do solo.

Do mesmo modo, vivem as palavras e as sementes, enxertadas em "palavras-sementes", por meio desse hífen que a camponesa insere. Risco ou talho, esse símbolo diacrítico, no universo da escrita, devolve o poema à sua condição de agricultura, conforme a interpretação aqui proposta. Opera-se, pois, a passagem do greffe ao graphe (DERRIDA, 1972), em uma pequena marca gráfica no interior do substantivo composto, como ramo de planta que liga a palavra e a semente, alimentando de seiva ambos os membros dessa poética rural.

No poema, somos ainda apresentados ao sintagma "signos férteis". A fertilidade do signo está em sua capacidade de produzir significados abundantes. A expressão "trigais do sentido" reforça essa ideia, pois o plural aplicado ao termo "trigais" implica uma variedade de plantios do cereal. Há nesses versos uma negação da lógica da monossemia. Os signos são férteis de sentido, ou seja, os seus significantes não correspondem apenas um significado último e verdadeiro, mas diversas safras semânticas.

Além de gerar uma multiplicidade de significados, a fertilidade dos signos também age sobre a camada significante, "dourando enunciados". Como um fruto que era verde e ao amadurecer ganha cor, o enunciado reveste-se de dourado, ganha brilho no processo da enuncia- 
ção poética. Enquanto a linguagem cotidiana centra-se na comunicação e, por isso, priva-se de vários recursos de estilo que poderiam prejudicar o entendimento da mensagem, na linguagem poética - intransitiva - as palavras são propositalmente arranjadas de modo a causarem, por meio do som e da aparência, diferentes efeitos de sentido. A objetividade dos enunciados é posta de lado e a criação de imagens poéticas passa a ditar a estrutura do texto. Isso reduz a distinção significante-significado, pois a significação está contida no próprio modo como se dá a junção das palavras e frases na linguagem poética (KRISTEVA, 1974). Dourar um enunciado é, portanto, dar opacidade ao seu caráter material, chamando-lhe atenção para a imanência do texto.

Nos versos seis e sete, é expresso o ciclo da vida vegetal em que a "palavra-poesia" é, ao mesmo tempo, "fruto e semente". Semente e fruto são elementos de uma cadeia em que não é possível determinar a origem, pois a semente gera o fruto e do fruto se extrai a semente. Podemos vislumbrar na palavra-poesia um ciclo vital interminável análogo à cadeia infinita de significantes que Jacques Derrida (1973) vislumbrou no signo. A semente e o fruto estariam para a palavra-poesia como o significante e o significado estão para o signo. O signo não possui um sentido final porque seu significante gera significados que, por sua vez, tornam-se significantes, que levarão a novos significados e assim por diante, infinitamente. Do mesmo modo, a palavra-poesia, ao ser semeada, torna-se árvore, que dá flores, que viram frutos, que contêm sementes, que se tornarão novas árvores. Não há início ou fim na cadeia da vida vegetal: da semente à árvore adulta - ou da palavra inicial ao ponto supostamente final de um poema -, tudo faz parte de um mesmo processo de escritura.

Esse processo, no entanto, não ocorre de maneira linear, e sim de modo rizomático (DELEUZE; GUATTARI, 1995), retomando aqui outra metáfora vegetal da escrita, cara ao pós-estruturalismo francês. Uma planta não cresce apenas longitudinalmente, com simetria bilateral; vegetais crescem para cima, para baixo e para todos os lados, apresentando um modelo de simetria radial, que se espraia de forma irregular, mas constante, tal qual o rizoma. No texto de Marilza Ribeiro, o crescimento das safras poéticas é multidirecional, em que o enunciado se espraia, fazendo semblant de rizoma, como vemos no $8^{\circ}$ verso 
("rompendo pelos campos") e também no adjetivo "enormes", o qual qualifica "safras" no $11^{\circ}$ verso.

Tal modelo tabular (não linear) de crescimento do vegetal-poema é também paradigma da plurideterminação do sentido na linguagem poética. O funcionamento simbólico da linguagem se dá como paragrama dinâmico (KRISTEVA, 1974, p. 107), em que a poesia apresenta-se como trama de elementos fonéticos, semânticos e sintagmáticos em movimento. As plantações de Marilza Ribeiro, que rompem e se agigantam pelos campos, constituídas de vegetais que sulcam a terra com suas raízes e preenchem o espaço com ramos em todas as direções, exemplificam bem essa dimensão rizomática da linguagem poética. Nesse contexto, a intertextualidade da linguagem poética é representada pelas plantas que, sozinhas, constituem poemas em si, mas que, em conjunto numa plantação, representam uma vasta rede de textos em diálogo.

Sobre a "turbulência do imaginário", referida pela camponesa no $9^{\circ}$ verso e causada por essa multiplicação tabular das plantações de palavras, aos olhos do leitor, cabe ressaltar que a literatura é produzida a partir da recusa dos homens em aceitar que não há um paralelismo entre o real e a linguagem:

O real não é representável, e é porque os homens querem constantemente representá-lo por palavras que há uma história da literatura. Que o real não seja representável — mas somente demonstrável pode ser dito de vários modos: quer o definamos, com Lacan, como o impossível, o que não pode ser atingido e escapa ao discurso, quer se verifique, em termos topológicos, que não se pode fazer coincidir uma ordem pluridimensional (o real) e uma ordem unidimensional (a linguagem). Ora, é precisamente a essa impossibilidade topológica que a literatura não quer, nunca quer render-se: o real não cabe na linguagem. O real é tridimensional, a escrita é bidimensional. (BARTHES, 1994, p. 21).

Nesse sentido, os textos poéticos podem ser chamados de textos do imaginário, já que a literatura, em sua pretensão de representar o real, é apenas capaz de jogar com uma aparência de verossimilhança. A turbulência dos textos do imaginário advém do fracasso inerente às produções da linguagem. Barthes (1994) dá a essa função perversa da literatura o nome de função utópica. Graças a essa utopia, os expedien- 
tes que os poetas utilizam para apreender o real são sempre falhos e com isso a arte poética é sempre renovada.

Mas o esforço dos poetas não é o bastante para fazer completar o processo da escritura. É apenas no espaço do leitor que a linguagem poética se realiza. A safra é colhida pelo próprio leitor, sem a presença da camponesa:

enormes safras colhidas

pelos olhares com fome

do saber profundo

A imagem da colheita pressupõe uma ideia de preservação da planta, pois quando se colhe um fruto, procura-se manter o restante da planta intacta para que continue frutificando. Não contemplamos o vegetal por completo porque ele tem suas raízes na terra e desenterrá-lo poderia matá-lo. Ou seja, a planta só vive enquanto tiver suas raízes escondidas de nós. Assim acontece com a poesia, que não entrega todos os seus significados aos leitores. Sempre que se pensa chegar a um sentido final, novos significantes brotam, gerando novos significados, que gerarão novos significantes, e assim sucessivamente. A linguagem poética é uma planta de raízes profundas, que estão além do nosso alcance.

Os "olhares com fome" são uma metonímia do leitor, que entra no domínio rural e se torna um colhedor, a fim de completar o ciclo agrícola da poesia. A associação do seu olhar à fome cria uma sinestesia que se justifica na medida em que a colheita remete não apenas ao fruto da terra, mas também ao fruto da língua: a poesia. A safra é colhida para saciar a fome; o ser humano planta para alimentar-se dos frutos da plantação. Porém, se entendermos que a plantação faz brotar poemas, então a colheita deve ser deglutida também pelos olhos, órgãos da leitura.

Assim se desvenda o ser total da escritura: um texto é feito de escritas múltiplas, saídas de várias culturas e que entram umas com as outras em diálogo, em paródia, em contestação; mas há um lugar onde essa multiplicidade se reúne, e esse lugar não é o autor, como se disse até o presente, é o leitor: o leitor é o espaço mesmo onde se inscrevem, sem que nenhuma se perca, todas as citações de que é feita uma escritura (...) (BARTHES, 1998, p. 70). 
Não são as motivações do autor que dão unidade ao texto poético, mas as necessidades do leitor. Com isso, a metáfora da "palavra-semente" leva-nos a pensar em outras metáforas implícitas: a da palavra-fruto e a da palavra-alimento. $O$ processo da escritura completa-se quando o texto vai ao encontro do leitor para alimentá-lo. Esse, por sua vez, saciará sua fome atribuindo sentidos ao texto poético.

Na realidade, todo poema é coletivo. Em sua criação intervém, tanto ou mais ainda que a vontade ativa ou passiva do poeta, a própria linguagem de sua época, não como palavra já consumada, mas em formação: algo como um querer dizer da própria linguagem. Depois, queira ou não o poeta, a prova da existência de seu poema é o leitor ou ouvinte, verdadeiro depositário da obra, que, ao lê-la, a recria e lhe outorga sua significação final. (PAZ, 1982, p. 339).

Porém, as significações do texto serão tão variadas quanto são variados os leitores. Disso decorre uma abundância de "Palavras-árvores" das quais os leitores podem se servir no $15^{\circ}$ e no $16^{\circ}$ versos do poema, sendo que o uso de reticências ainda abre a possibilidade de imaginarmos muitas outras espécies além das expressamente citadas:

mognos... ipês... aroeiras... oliveiras...

cerejeiras... pessegueiros... mangueiras...

Nos versos que seguem, a voz lírica afirma novamente sua identidade de "camponesa", mas agora acrescentando que é também "jardineira". Um camponês é alguém que planta no amplo e aberto espaço do campo. Já o jardineiro atua no pequeno e restrito espaço de um jardim. A clausura do jardim faz da jardinagem uma atividade de quem planta para si. Logo, temos no verso a imagem de uma poetisa que alterna entre estados de extroversão e introversão. Quando sua poesia abre-se para o exterior, ela é camponesa, mas quando sua poesia permite-lhe usufruir de um momento intimista, é jardineira. É no jardim que a linguagem poética age como um meio para que ela acesse suas questões subjetivas.

A jardinagem também pode significar que o trabalho do eu lírico não se restringe a plantas comestíveis. Sua lida abrange plantas ornamentais, ou seja, aquelas usadas para enfeitar e perfumar os espaços. Essa ornamentação simbolizaria um apreço pelo aprimoramento estéti- 
co da matéria formal do verbo. E alguns dos recursos da língua que ela aprimora esteticamente são citados:

\author{
planto em minha roça \\ sílabas, metáforas, frases \\ tudo floresce e frutifica
}

Há uma gradação ascendente na sequência "sílabas, metáforas, frases". Primeiro, a sílaba, que representa um fonema ou conjunto de fonemas que são pronunciados numa emissão de voz. São unidades que, normalmente, precisam unir-se a outras para formar palavras. Já a metáfora constitui uma figura de linguagem que pode ser expressa por uma palavra ou conjunto de palavras, ou seja, é um recurso de sentido maior e mais expressivo que a unidade de uma sílaba. Por fim, a frase é um enunciado de sentido completo que pode se dar pelo uso de uma ou mais palavras, podendo ainda conter figuras de linguagem como estratégias estilísticas. Assim, temos uma sequência de elementos linguísticos que vão de uma unidade menor a uma maior, em que cada unidade contém todas as outras do nível anterior. Se essa metáfora explica bem a estrutura de superordenação dos elementos da língua, também vale para a morfologia vegetal. Afinal, na semente, já residem em potência - esperando o plantio e o cultivo - caule, folhas, flores e frutos.

Do mesmo modo, à gradação das unidades linguísticas corresponde à evolução do cultivo. A atividade literária faz crescerem significantes linguísticos no papel, do mesmo modo que a atividade agrícola faz crescer plantas na terra.

A camponesa diz que essas unidades da língua florescem e frutificam, o que denota um processo de metamorfose. Ao ser plantada, a semente sai do seu estado estanque e modifica-se, cresce como árvore, dá flores e frutos. A mesma metamorfose mostra o quanto a língua pode adquirir significados diversos no âmbito da literatura. Esse caráter polissêmico da poesia é atestado por Julia Kristeva, para quem a linguagem poética nega a lógica da significação, pois ela é, ao mesmo tempo, um ser e um não ser (1974, p. 183). O discurso não poético determina que palavras não são sementes e não podem florescer e frutificar. No entanto, na poesia, essa proibição é superada: sílabas, metáforas e frases tornam-se algo que não eram (sementes, flores, frutos), sem deixar 
de ser o que são (recursos da língua). Esse efeito simultâneo de ser um e ser outro é algo próprio da linguagem poética:

$\mathrm{O}$ poeta nomeia as coisas: estas são plumas, aquelas são pedras. $\mathrm{E}$ de súbito afirma: as pedras são plumas, isto é aquilo. Os elementos da imagem não perdem seu caráter concreto e singular: as pedras continuam sendo pedras, ásperas, duras, impenetráveis, amarelas de sol ou verdes de musgo: pedras pesadas. E as plumas, plumas: leves. A imagem resulta escandalosa porque desafia o princípio de contradição: o pesado é o leve. Ao enunciar a identidade dos contrários, atenta contra os fundamentos de nosso pensar. Portanto, a realidade poética da imagem não pode aspirar à verdade. $O$ poema não diz o que é e sim o que poderia ser. Seu reino não é o do ser, mas o do ‘impossível verossímil' de Aristóteles (PAZ, 1982, p. 120)

As sílabas, metáforas e frases, quando inseridas em um contexto de comunicação cotidiana, em que o conteúdo importa mais que a tessitura dos significantes, são limitadas pelas regras da língua que determina o que deve ser omitido e o que deve ser obrigatoriamente expresso. Porém, quando esses mesmos elementos que compõem a linguagem cotidiana são desviados do propósito comunicacional, surge a possibilidade de aplicar-lhes novos significados. Trata-se de uma subversão dos desígnios instrumentais dos significantes. Essa subversão é atributo do que é chamado por Barthes de literatura. Ao descrever como essas unidades linguísticas florescem e frutificam, o poema remete ao processo de trapaça que a literatura efetua no seio da língua, para que essa "aflore":

Entendo por literatura não um corpo ou uma sequência de obras, nem mesmo um setor de comércio ou de ensino, mas o grafo complexo das pegadas de uma prática: a prática de escrever. Nela viso, portanto, essencialmente, o texto, isto é, o tecido dos significantes que constitui a obra, porque o texto é o próprio aflorar da língua, e porque é no interior da língua que a língua deve ser combatida, desviada: não pela mensagem de que ela é o instrumento, mas pelo jogo das palavras de que ela é o teatro. (BARTHES, 1994, p. 16, grifo nosso).

O afloramento da língua parte da memória na qual se fixam as raízes da escritura. A memória age no resgate dos textos do passado, 
cuja referência é basilar na construção de todo novo texto, segundo os pressupostos de intertextualidade e interdiscursividade: "Sentindo a memória das raízes". Assim como as raízes do vegetal extraem da terra os nutrientes que o sustentam, o texto poético enraíza-se num espaço intertextual, extraindo sentidos de outros discursos e formando com esses um processo de diálogo: "o texto poético é produzido no movimento complexo de uma afirmação e de uma negação simultâneas de um outro texto". (KRISTEVA, 1974, p. 187).

O diálogo nunca se esgota, já que a cadeia de significantes não para de aumentar, o que inibe qualquer interpretação totalizadora - ou totalitarista. Não se pode chegar a uma interpretação definitiva de um texto, pois ele se situa numa rede em que surgem sem cessar novos textos que dialogam com ele e atribuem-lhe novos sentidos. Por isso, em "Poética Rural", a "escrita" é caracterizada como "enigmática". O sentido derradeiro do texto literário é inapreensível, pois "a literatura não diz que sabe alguma coisa, mas que sabe de alguma coisa" (BARTHES, 1994, p. 18). As tentativas de resolver o enigma do significado produzem resultados obscuros e provisórios. Mas é justamente nessa opacidade do texto literário que reside o gozo da leitura, pois a língua é opressora, fascista naquilo que obriga a dizer. A liberdade só pode se encontrar no logro da língua que é a literatura. (BARTHES, 1994).

Nos últimos versos, a camponesa conclui que sua poesia vem de um lugar inacessível a ela própria:

saindo do fundo

mais profundo do meu fundo

tão fecundo

dentro de mim.

A repetição do termo "fundo", incluindo aí a paronomásia contida em profundo e em fecundo, produz a imagem da palavra propagando pelo interior da escritora num percurso tão distante e profundo que acaba por provocar ecos, tal qual por dutos subterrâneos onde dormem as sementes dessa poética. A sílaba tônica dos vocábulos supracitados recai na vogal grave, fechada, velar e posterior /u/, cuja articulação cerrada evoca a sensação de obscuridade. É desse sulco na terra, ou na 
língua, que brotam as plantas e os poemas, extraindo sua seiva de um mais além - escuro, misterioso, profundo - para vivificar na folha, seja ela de verde plantação ou de papel para a escrita.

\section{CONSIDERAÇÕES FINAIS}

A poesia ruralizada é expressão do caráter vivo da linguagem. A língua - palavra em estado de semente - precisa ser plantada em terra fértil para crescer e frutificar em forma de literatura. $\mathrm{O}$ sulco na terra com o arado é rastro do camponês na plantação assim como o sulco no papel com a escrita é rastro do escritor. O rastro mostra a passagem de alguém, mas essa passagem só se atesta pela ausência. Se a plantação/escritura só se dá na ausência, não há como falar em escritura sem pensar na falta da origem absoluta do sentido (DERRIDA, 1973, p. 80).

Assim, a voz lírica que semeia palavras e colhe poesia é mera cultivadora da linguagem. Ela não arroga para si a função de desvelar os significados dos signos. Pelo contrário, assume que sua escrita - mesmo que saída de seu interior - é enigmática. É na ausência de sentido absoluto que se constitui a poeticidade de sua plantação. Embora se reconheça como escritora, a camponesa/jardineira não se posiciona como uma autora que teria controle absoluto da origem e dos fins de seus poemas. A linguagem poética que dela brota vem de uma profundeza obscura, dando sinal do que há no interior da escritora, mas sem revelar-se plenamente.

Se, para Barthes (1994), a literatura define-se na metáfora da trapaça e do jogo no seio da língua, em "Poética Rural", Marilza Ribeiro define-a como palavra florida e frutificada a partir da semente da língua. Os poetas jogam com as formas e sentidos das palavras para libertarem-se das amarras impostas pela língua. Nos versos analisados, verifica-se que o jogo do eu lírico é a agricultura; é como atividade agrícola que se elabora - ou cultiva - a linguagem poética. Nessa perspectiva, o jogo é expresso nas imagens da plantação como escritura; da camponesa/ jardineira como poeta; e da colheita como fruição.

Em "Poética Rural", o conceito de poeta coaduna com os pressupostos pós-estruturalistas que negam ao autor a potência sobre o texto, 
uma vez que o ato de cultivar difere do ato de criar. O cultivo da linguagem poética pressupõe a ideia de que a "palavra-semente" possui em si o potencial para crescer, independentemente da intervenção humana. Um agricultor, por mais que regue, adube e cuide para que sua plantação cresça saudável, não se autoproclama criador dos vegetais que colhe. De modo análogo, há nos versos de Marilza Ribeiro uma voz lírica que vê suas palavras plantadas ganharem corpo e forma para além de seu controle, atestando a liberdade da palavra na poesia.

\section{The CUlTIVATION OF THE WORD IN “POÉTICA RURAL”, By Marilza Ribeiro}

\section{ABSTRACT}

In this paper we investigate how the poem "Poética Rural", by Marilza Ribeiro, discusses the process of writing poetry. The poem is constituted as a metalinguistic exercise, wherein the labor of poetic creation is presented through the metaphor of rural labor. Through the analysis of the formal aspects that ascribe meaning to the text and with the aid of literary semiotics, we demonstrate how the poem reflects on the concepts of death of the author, the polysemy of poetic language and literature as a cheat on language; all these concepts are crucial in French post-structuralism. In the analyzed verses, the lyrical self plays with language and elaborate poetic language by agricultural activities.

KeYwords: Marilza Ribeiro, Poetry, Metalanguage.

El cultivo de la palabra en “poética rural”, de Marilza Ribeiro

\section{RESUMEN}

En este artículo investigamos cómo el poema «Poética Rural», de Marilza Ribeiro, problematiza el proceso de escritura de la poesía. El poema se constituye como un ejercicio metalingüístico, en el cual el labor de la creación poética es presentado por medio de la metáfora del trabajo rural. Mediante el análisis de los aspectos formales que dan sentidos al texto y con el apoyo de la semiología literaria, demostramos cómo el poema refleja los conceptos de la muerte del autor, la polisemia del lenguaje poético y la literatura como trampa en el lenguaje, caros al pos estructuralismo francés. En los versos analizados, se 
verifica como el yo lírico juega con la lengua y elabora el lenguaje poético a través de la actividad agrícola.

Palabras clave: Marilza Ribeiro, Poesía, Metalenguaje.

\section{REFERÊNCIAS}

BARTHES, R. Aula. Traduzido por Leyla Perrone-Moisés. São Paulo: Cultrix, 1994.

. A morte do autor. In: O rumor da língua. Traduzido por Mário Laranjeira. São Paulo: Editora Brasiliense, 1998. tiva, 1987.

. O prazer do texto. Traduzido por J. Guinsburg. São Paulo: Perspec-

. Uma problemática do sentido. Traduzido por Ivone Castilho Benedetti. In: Inéditos I: teoria. São Paulo: Martins Fontes, 2004.

DELEUZE, Gilles e GUATTARI, Félix. Mil platôs - capitalismo e esquizofrenia. Rio de janeiro: Ed. 34, 1995.

DERRIDA, J. Gramatologia. Traduzido por Miriam Schnaiderman e Renato Janini Ribeiro. São Paulo: Perspectiva, 1973.

KRISTEVA, J. Poesia e Negatividade. In: Introdução à semanálise. Traduzido por Lucia Helena França Ferraz. São Paulo: Perspectiva: 1974.

PAZ, O. O arco e a lira. Traduzido por Olga Savary. Rio de Janeiro: Nova Fronteira, 1982.

RIBEIRO, M. Poética Rural. (no prelo).

Submetido em 28 de novembro de 2014.

Aceito em 03 de agosto de 2015.

Publicado em 21 de agosto de 2015 